Fecha de recepción: agosto 2014 Fecha de aceptación: octubre 2014 Versión final: marzo 2015

\section{Entre al álbum y el MP3: variaciones en las tecnologías y las escuchas sociales}

Rosa Chalkho *

Resumen: El artículo ensaya relaciones entre el surgimiento y desarrollo de las tecnologías de grabación y reproducción del sonido y los modos en que estas innovaciones se entrecruzan con la producción de música y arte sonoro, destacando la cuestión cultural las condiciones de producción como determinantes de las prácticas. A partir de esta temática el texto se propone discutir algunas tradiciones naturalizadas que habitan los discursos sociales respecto a la asociación de lo tecnológico con el progreso y a la consideración lineal de los inventos técnicos.

Palabras clave: sonido - tecnologías - arte sonoro - música - audiovisual.

[Resúmenes en inglés y portugués en la página 82]

${ }^{(*)}$ Profesora de Artes en Música (IUNA). Magister en Diseño (Universidad de Palermo). Docente de grado y posgrado de la Facultad de Diseño y Comunicación de la Universidad de Palermo. Docente de la Facultad de Arquitectura, Diseño y Urbanismo de la Universidad de Buenos Aires.

Existen algunos supuestos naturalizados en torno a las cronologías, usos y beneficios de los inventos tecnológicos, y en especial en la tecnología de consumo, que resultan interesantes de poner en discusión. Estas concepciones circulan en los discursos sociales y funcionan como modeladoras de prácticas, tanto en las instancias de producción como en la recepción. Uno de los mitos arraigados es que cualquier invento tecnológico es superador de su antecedente, idea que aparece como heredera del concepto de progreso del Positivismo, en la que la técnica es una construcción ascendente y sin dudas benefactora. Respecto a las tecnologías del audio, a modo de ejemplo, el soporte de circulación más difundido en la actualidad es el formato de compresión llamado MP3, que si bien representa una mejora en algún aspecto ajeno al sonido, como la portabilidad y las ventajas para su tráfico digital, la calidad del audio verifica una pérdida sustancial. No solo el MP3 representa una degradación en las condiciones de escucha, también los distintos soportes de reproducción como sistemas de audio hogareños, teléfonos o auriculares no sostienen la calidad de la escucha como un valor. En este sentido, es interesante comparar las condiciones actuales con los hábitos de escucha de la música reproducible de hace unas décadas, por ejemplo, en los años 70 se verifica un pico en la producción de sistemas de audio Hi-Fi 
(High Fidelity o Alta Fidelidad) para consumo hogareño. Estos equipos formaban parte del estatus de aspiraciones de las clases medias por un lado, y por otro, pueden ser leídos como signos culturales de una manera social de escuchar la música en la que la gente se reunía a oír discos en grupo. Un cambio de tecnologías no comporta solamente cambios en equipos, aparatos, calidades o ventajas, también trae aparejados modos de percepción, hábitos sociales y consumos culturales.

Otro de los mitos, menos evidente pero no por eso menos sustancial, es la suposición que los inventos o innovaciones tecnológicas parten de necesidades preexistentes. En relación al audio, una mirada sobre la historia de los aparatos demuestra que ninguno de los pioneros de estas invenciones (Edison, Graham Bell o Scott entre otros) pensó en la reproductibilidad, industrialización y comercialización de la música como fin, sino antes bien, en la idea del sonido como documento o en aplicaciones para ayudar a los sordos mediante gráficos. La manera en que el uso social de la reproductibilidad gana el espacio construyendo una de las industrias culturales más poderosas del siglo XX comprueba que una historización de los aparatos nada dice por sí misma sin el análisis de la cultura y de las condiciones de producción en las que esos artefactos se desarrollan.

Cuando se inventaron los primeros equipos de transducción ${ }^{1}$ del sonido su finalidad era muy distinta a la que actualmente conocemos. Estas primitivas máquinas fueron pensadas para fines médicos, como herramientas de comunicación y más tarde, cuando se logró fijar el sonido en un soporte, su utilización originaria fue concebida para registrar documentos sonoros de la historia. La tecnología estaba allí, pero tendrían que pasar algunas décadas para que los cambios culturales permitan advertir el poder social y económico de la reproductibilidad de la música y su consecuente transformación en la matriz perceptual de las sociedades. Este cambio de paradigma atraviesa dos escalones, el primero es la invención de la fijación (grabación del sonido) con objetivo documental, de conservación del sonido para la posteridad (discursos ejemplares de presidentes, científicos, etc.), familiar (como recuerdo o "fotografías sonoras"), educativo y hasta legal.

Al respecto Thomas Alva Edison en 1890 imagina todo tipo de aplicaciones del fonógrafo: un álbum familiar sonoro que guarda el recuerdo de las voces de los muertos, las lecciones de un profesor, los libros para ciegos, etc. En este contexto, la grabación de la música también tiene un carácter documental: "Fragmentos orquestales, e incluso óperas enteras pueden almacenarse en el cilindro: la voz de Patti cantando en Inglaterra puede escucharse de este lado del Atlántico y conservarse para las futuras generaciones"2.

El segundo escalón es la reproducción a escala creciente de la música, que implica el nacimiento de una nueva industria incentivada por las mejoras técnicas, que entre sus cambios sobresalientes incluyen el paso del cilindro al disco y la grabación eléctrica. Recién hacia 1930 tanto la grabación como las máquinas de reproducción alcanzan un estándar de audio aceptable y caminan ya sobre el nuevo terreno de la reproductibilidad de la música, establecida también en alianza con la radio como medio de difusión. La función originaria del almacenamiento documental rota en este período hacia una función de esparcimiento en el cual las tecnologías de grabación y reproductibilidad se aglutinan en los procesos de producción de la industria del disco.

Es interesante considerar que los principios tecnológicos que darán pie a la posterior grabación y reproducción del sonido existían ya desde 1857 cuando León Scott inventa una 
primitiva máquina que transduce de manera mecánica el sonido para representarlo gráficamente, mediante una aguja estilográfica que "dibuja" la variación de las ondas sonoras comparable a un oscilograma actual a la que llama fonotógrafo. En 1874 Alexander Graham Bell construye otra versión del fonotógrafo cuyo objetivo es ayudar a los sordos a "escuchar el sonido con los ojos" (Sterne, 2006). Su idea era construir toda una alfabetización en base a los gráficos de las formas de onda dibujadas por el aparato cuya decodificación de gráficos a sonidos alfabéticos pudiera enseñarse a los sordos para poder así "leer el sonido"; pero pese a dirigir sus esfuerzos inventivos e insistir con la posible eficacia, su método obviamente no funcionó. Es decir, serán necesarias varias décadas para que el desarrollo tecnológico de la mano de las transformaciones sociales construyan el cambio; para que el artificio pase de curiosidad científica a una nueva plataforma en la manera de producir y escuchar música.

La consolidación del disco no solo crea músicas nuevas que devienen de populares en masivas en su pasaje de lo vernáculo a la cultura de masas, sino que también cambian las músicas del pasado y su manera de ser interpretadas. Un ejemplo atípico, pero no por ello menos resonante, lo constituye la posición del célebre pianista canadiense Glenn Gould, quien en un momento álgido de su carrera abandona la interpretación en vivo para abrazar devotamente la grabación en estudio, a conciencia de todas las manipulaciones de posproducción que esto implica. Al respecto expresa: “(...) debemos estar dispuestos a aceptar el hecho de que, para bien o para mal, la grabación alterará para siempre nuestras nociones sobre lo que es apropiado a la interpretación de la música” (Gould, 1989: 412). Casualidad o no, el surgimiento del cinematógrafo presenta ribetes análogos al nacimiento de la grabación sonora. Para los hermanos Lumière el invento es una mera curiosidad, y la anécdota relata que Antoine Lumière se niega a vendérselo a George Méliès -quien sí reconoció inmediatamente su potencial de espectáculo- con las siguientes palabras citadas por Joseph-Marie Lo Duca en su Historia del Cine: “Joven, el invento no se vende. Y agradézcame, porque para usted sería la ruina. Puede ser explotado algún tiempo como una curiosidad científica, pero fuera de eso no tiene ningún porvenir comercial” (1960:11). Con la consolidación de la reproducción de la música convertida en industria el campo musical se fractura, pero de manera encubierta. En las instancias de producción su lógica adopta los mecanismos de la cadena de montaje fordista, desde el cool hunting o caza de talentos hasta la terminación del producto pasando por la producción artística y musical, la contratación de sesionistas y el diseño de imagen, gráfica y publicidad entre las principales etapas de producción. De alguna manera en el siglo XX, música popular es un eufemismo para música industrial. La diferencia es que en las instancias de recepción, el aspecto serial, maquínico y comercial está velado. Los consumidores no compran discos como comprarían cualquier otro objeto de diseño industrial, sino que se cree de manera apasionada en la legitimidad y autenticidad artísticas.

Al respecto, Jacques Attali enuncia en su libro Ruidos:

Hoy en día la música emerge ante todo por su componente comercial, es decir por la canción popular, comercializada por la radio. El resto de la producción, la música culta, se inscribe aún en la línea de la representación y en su crisis; constituye aparentemente, un campo totalmente distinto del que 
la mercancía está excluida, en el que el dinero es indiferente. (...) Al contrario que en los siglos anteriores, música popular y música culta, música inferior y música superior han roto sus relaciones del mismo modo que la ciencia ha roto las suyas con las aspiraciones de los hombres. (1977, p. 205).

La música se alejó del campo del arte para auto-incluirse en la esfera del entretenimiento. En la pugna por la definición legítima de la Música (cuya consecuencia en la discursividad es la distinción acerca de lo que es y lo que no es música) las expresiones derivadas de las vanguardias y posvanguardias del siglo XX han quedado relegadas, o en otras palabras han perdido la batalla por el nombre. En tanto que las estructuras masivas de gusto han relegado al experimentalismo musical con frases como "pero esto sin melodía y si ritmo no es música" también los compositores en los últimos años han abandonado la pelea articulando un nuevo concepto denominador de las producciones: el arte sonoro. Semánticamente, "arte sonoro" bien puede ser sinónimo de la definición histórica para la Música, pero con énfasis en la palabra Arte, reafirmando la pertenencia a este campo antes que todo.

En la esfera del Arte sonoro resuena como propia la idea de la expansión. En tanto que la Música sigue acarreando la dialéctica músico - público (o producción y recepción) el concepto de Arte sonoro alude a una apertura no sólo en las producciones sino en los modos en que las obras circulan y se recepcionan. Sus circuitos no son los de la industria (fabricación de discos, producción de conciertos, difusión radial y televisiva, etc.) sino que su circulación adopta modos similares a la de las artes visuales, como los conciertos en museos de arte contemporáneo, las galerías, las instalaciones sonoras, los festivales, la legitimación mediante premios o residencias artísticas y la difusión por medio de net labels autogestionados.

Parafraseando a Theodor Adorno, arte e industria son irreconciliables. El mingitorio de Marcel Duchamp o la caja brillo de Andy Warhol parecen reafirmar esta fractura aún llevándola al límite de su cuestionamiento. La corrosiva obra de Duchamp no convierte a todos los mingitorios como productos industriales en arte, sino que paradojalmente la historia invistió de aura a los pocos que circulan por el mundo, los que Duchamp "tocó". La crítica habita al interior del campo del arte, en tanto que a la industria no le mueve un pelo. Desde otro foco, la obra de Warhol coquetea con una estetización de lo industrial, pero sus piezas no se confunden en verdad con la góndola real de un supermercado.

La definición de Arte expandida en el siglo XX hacia todos sus extremos guarda para sí algunas (muy pocas) invariantes; por un lado "que nadie entre aquí si tiene preocupaciones comerciales" (1997:150), sintetiza Pierre Bourdieu la negación o denegación de lo económico como su objetivo principal y por lo tanto su distinción con la producción industrial, y por otro lado un gen crítico más o menos evidenciado,

Como lo anticipamos, en el campo de la Música, el corte entre Arte e Industria está solapado, el concepto de industria cultural acuñado críticamente por Adorno se desnegativiza en pos del concepto de la "pata necesaria" que posibilita los medios de producción y difusión de la actividad musical, las compañías discográficas ocuparon el lugar de las enemigas necesarias de los músicos.

La utilización social del término música aleja cada vez más al concepto moderno de Música (como arte del sonido) del campo del Arte y lo acerca cada vez más al rubro del "en- 
tretenimiento". Ya Adorno había cuestionado fuertemente su industrialización excluyendo de manera radical del campo de lo artístico cualquier música popular devenida en cultura de masas justamente por efecto de esta factura, lo que hoy llamamos la "música enlatada". Desde el punto de vista de las acciones de política cultural estatal, la promoción de estas industrias puede considerarse como positiva siempre y cuando se tenga en cuenta que el fomento está orientado a lo industrial y no a lo artístico, cuestiones que suelen confundirse en el campo de la gestión cultural, ya que aunque los productos sean bienes simbólicos pertenecen a la producción a escala y; estas acciones de incentivo a la industria no necesariamente implican un "derrame" de recursos hacia el campo del arte y de las nuevas tendencias en experimentación sonora.

Sin embargo, la relación entre arte e industria no siempre es explicable mediante la dialéctica negativa. Aunque la distinción de opuestos constituye un interesante punto de partida para balizar el objeto de estudio, inmediatamente resulta necesario estudiar las relaciones, maridajes y desencuentros entre las prácticas. Justamente es en lo tecnológico donde se tejen las redes que relacionan las prácticas industriales con las emergentes: las primeras generando los bienes de producción que posibilitaron tanto las nuevas perspectivas artísticas como la democratización y el acceso a la producción ${ }^{3}$. Desde otro punto de vista, la experimentación musical alimenta mediante investigaciones y prototipos el adelanto tecnológico, como fue el caso de la espacialización del sonido. La octofonía que aparece como el sistema de audición para la música electroacústica es la matriz para el desarrollo estandarizado del sonido surround para el cine. Justamente la espacialización del sonido constituye la herramienta mas poderosa de las narrativas inmersivas, seguramente su efecto de "realidad virtual" es más poderoso que el de la imagen, que aún permanece atrapada en el encuadre de la (o las) pantallas. En tanto que podemos distinguir entre la imagen del mundo real y la imagen en pantalla, aún con los más sofisticados sistemas de realidad virtual no es posible confundirnos con el mundo real, sabemos que estamos viendo imágenes, el sonido sí es capaz de confundir acerca de lo que suena naturalmente o está generado por un sistema de audio.

Las tecnologías expandidas no son simplemente una confluencia de artificios técnicos sino que implican una variación del orden epistémico que conlleva (mas allá de las posibilidades tecnológicas) un cambio perceptual, un cambio en las prácticas tanto de producción como de reconocimiento, un giro más dentro de la revolución epistémica de la multiperspectividad iniciada por las vanguardias del siglo $\mathrm{XX}^{4}$.

En tanto confluencia sensorial, esto no es algo nuevo, ya la ópera como género que nace y se desarrolla a la par de la era moderna aglutina diversas disciplinas artísticas y la combinación de la visión y la audición. Sin embargo, una gran distancia separa la multidisciplinariedad presente en la ópera de las propuestas performativas del arte sonoro, y esta división no solo es tecnológica, sino que abarca toda una rotación conceptual en el cuño mismo de la definición de música.

Para que existan propuestas de arte generativo o interactivo no alcanza con las posibilidades del artificio tecnológico sino deben existir matrices de percepción cultural dispuestas para producirlo, percibirlo y comprenderlo. En este sentido, es interesante la definición del artista mexicano Manuel Rocha Iturbide: "Arte sonoro es un concepto artificial que surge como una necesidad de definir todo lo que no cabe dentro del concepto música" (Iturbide, 
s/f), en la cual la cualidad de artificialidad refuerza la arbitrariedad de las clasificaciones, y la idea de lo "que no cabe" dentro de la música alude a aquello que se está derramando o forzando sobre los límites.

Los artificios tecnológicos por sí mismos no necesariamente dan cuenta del carácter innovador de una obra. Ya en el siglo XIX la ópera echaba mano de cuanto artificio técnico fuera posible para construir una "obra de arte total" involucrando todas las artes y reclamando también a casi todos los sentidos, su lógica estética es la de la unidad y la confluencia, su concepto es el de la fuerza centrípeta atrayendo todos los elementos al vórtice de la unidad de sentido. Otro ejemplo de la confluencia centrípeta de elementos discursivos y tecnologías se observa en el cine clásico, que al lograr la consolidación de su discurso en el llamado "Modo de Representación Institucional" hereda y amplía la visión unicista de "obra". El Modo de Representación Institucional (M.R.I.) es un concepto acuñado por Nöel Burch para explicar el momento en que el cine consolida su discurso y su formato luego de atravesar toda una serie de experiencias y producciones diversas a las que Burch denomina Modo de Representación Primitivo (MRP). El MRI comienza aproximadamente en 1920 e implica toda una serie de tópicos, normativas y convenciones que regulan el conexionado, la forma de funcionamiento y producción de las representaciones cinematográficas. Tales regulaciones se extienden desde la normativización de los valores de planos hasta su articulación mediante el montaje como materia clave para la construcción discursiva. La tesis de Noël Burch es demostrar que lo que ahora percibimos como lenguaje cinematográfico naturalizado como los distintos tipos de planos, el contraplano, las secuencias y los signos que el cine utiliza se han ido creando e inventando y nada tienen que ver con el hallazgo de una supuesta universalización discursiva, común a toda percepción.

Si bien el concepto de obra de arte total se encuentra habitado por la polisemia y la metáfora como materia estética y sensible ineludible de lo artístico, sus elementos o cadenas discursivas (fotografía, montaje, narración, música, texto, escenografías, vestuarios, etc.) confluyen al eje y a la unidad, residen y actúan al interior de su universo. Todo converge al centro narrativo y el advenimiento del sonido sincrónico, a pesar de los temores de Serguei Eisenstein expresados en el Manifiesto del contrapunto sonoro, no devuelven al cine a una "teatralidad filmada" sino que confirman este discurso amasado en el tiempo y en las prácticas.

La expansión, en cambio actúa por fuerza centrífuga, estalla desparramando la unidad en otras tantas múltiples unidades de sentido, evidentes o furtivas que a veces ni siquiera habitan un lugar y tiempo comunes sino que se construyen o deconstruyen en diversos tiempos y espacios; que también incluyen a las topologías y temporalidades digitales e inmateriales. La multiplicidad y la expansión hieren al relato único y la comunicación como fin, pero en cambio amplían exponencialmente la artisticidad. Así como Derrida ensaya una definición condensada de la filosofía deconstructivista como "más de una lengua" ${ }^{6}$ las artes expandidas hablan múltiples discursos; no intentan nuclear los recursos instrumentales sino utilizar la versatilidad tecnológica para potenciar las infinitas derivas. 


\section{Notas}

1. La transducción del sonido es la transformación de la presión acústica (onda sonora) en señal eléctrica. En los primitivos equipos la transducción se refiere a la conversión de la presión acústica en un gráfico, sin mediar el componente eléctrico de modo que se trata de un cambio mecánico de un tipo de movimiento en otro.

2. Edison, Thomas (1891). Artículo reproducido y citado por la revista La Nature, 25 de abril de 1981. Citado en: Attali, Jacques Ruidos pag. 188.

3. En la actualidad es posible contar con un estudio doméstico (home studio) para la producción y post-producción de audio a un coste accesible, cuestión que resultaba muy difícil algunas décadas atrás.

4. Para ampliar sobre los conceptos de percepción, multiperspectividad y orden epistémico ver en el libro de Donald Lowe Historia de la percepción burguesa.

5. El concepto de Gesamtkunstwerk (obra de arte total) fue acuñado por el compositor Richard Wagner en el siglo XIX para caracterizar su estética operística.

6. "Si tuviera que arriesgar una sola definición de la deconstrucción, breve, elíptica, económica como una consigna diría: más de una lengua” (Derrida, 1985, p. 38).

\section{Bibliografía}

Adorno, T. y Horkheimer, M. (1998). Dialéctica de la ilustración: fragmentos filosóficos. Madrid: Trotta. Colección Estructuras y Procesos. Serie Filosofía.

Attali, J. (1977). Ruidos: ensayo sobre la economía política de la música. Valencia: Ibérica de Ediciones y Publicaciones.

Benjamin, W. (1989). La obra de arte en la época de su reproductibilidad técnica. Discursos Interrumpidos I. Buenos Aires: Taurus.

Burch, N. (1987). El Tragaluz del infinito. Madrid: Cátedra. Signo e imagen.

Bourdieu, P. (1995). Las reglas del arte: Génesis y estructura del campo literario. Barcelona: Anagrama. Colección argumentos.

Derrida, J. (1985). La voz y el fenómeno. Valencia: Pre-textos.

Eco, U. (1993). Obra abierta. Buenos Aires: Ariel.

Gould, G. (1989). Las perspectivas de la grabación. En: Escritos críticos. Madrid: Ediciones Turner.

Iturbide Rocha, M. (s/f).¿Qué es el arte sonoro? Disponible en: http://www.artesonoro.net/ artesonoroglobal/QueEsElArteSonoro.html

Lo Duca, J. M. (1960). Historia del cine. Buenos Aires: Eudeba.

Lowe, D. (1999). Historia de la percepción burguesa. Buenos Aires: FCE.

Negus, K. (2005). Los géneros musicales y la cultura de las multinacionales. Barcelona: Paidós.

Sterne, J.(2003). The audible past. Cultural origins of sound reproduction. Durham \& London:

Duke University Press. 
Summary: The paper essays the relations between the emergence and development of the technologies for recording and playback of sound, and the ways in which these innovations are intertwined with the production of music and sound art, highlighting the issue of cultural conditions as determinants of production practices. From this subject the paper aims to discuss some traditions that inhabit naturalized social discourses regarding the association of the technological progress and the linear account of technical inventions.

Keywords: sound - technologies - sound art - music - audiovisual.

Resumo: $\mathrm{O}$ artigo apresenta as relações entre o surgimento e desenvolvimento das tecnologias de gravação e reprodução do sonido e os modos como estas inovações se cruzam com a produção de música e arte sonoro, destacando a questão cultural, as condições de produção como determinantes das práticas. A partir desta temática o texto se propõe discutir algumas tradições naturalizadas presentes em discursos sociais em relação à associação do tecnológico com o progresso e à consideração lineal dos inventos técnicos.

Palavras chave: sonido - tecnologias - arte sonoro - música - audiovisual. 
Fecha de recepción: agosto 2014 Fecha de aceptación: octubre 2014 Versión final: marzo 2015

\section{Objetos-frontera: cruces entre ciencia, arte y tecnología. Generación de redes de conocimiento que presentan cambios en el paradigma cultural actual}

Alejandra Marinaro ${ }^{\star}$ y Romina Flores ${ }^{\star *}$

Resumen: En el presente trabajo analizamos cómo el arte tecnológico multimedial, a través del colectivo artístico como proyecto pedagógico, sirve para resignificar objetos-frontera mediante el trabajo artístico, la divulgación científica y los adelantos tecnológicos que no han sido concebidos para trabajar juntos pero que a partir de este entrecruzamiento, independiente de los resultados de cada área del saber, logran consolidar una nueva forma de trabajo integradora.

Palabras clave: multimedia - colectivo artístico - objeto-frontera.

[Resúmenes en inglés y portugués en la página 94]

${ }^{*}$ Escuela de Comunicación y Diseño Multimedial. Universidad Maimónides - Buenos Aires, Argentina (marinaro.alejandra@maimonides.edu)

${ }^{(* *)}$ Escuela de Comunicación y Diseño Multimedial. Universidad Maimónides - Buenos Aires, Argentina (flores.romina@maimonides.edu)

\section{Introducción}

(...) Es posible que diversas entidades misceláneas pertenezcan a un mismo mundo, cruzándose entre sí y formando, al hacerlo, complejos diseños, y, así, no procedemos a crear un mundo nuevo cada vez que separamos dos cosas o cuando volvemos a unir otras, esta vez de manera diferente. Pero los mundos pueden ser diferentes si no todo lo que a uno de ellos pertenece también a otro. (Goodman, 1990, p. 26)

A partir de la idea de multiplicidad de mundos de Goodman y algunas nociones históricas, vamos a analizar la cuestión del arte multimedial como vehículo que permite interrelacionar diferentes saberes a partir de la utilización de objetos-frontera que conviven en los intersticios de los diferentes mundos.

"La noción de objeto-frontera fue puesta en escena para analizar el contenido del trabajo colaborativo en general y en particular que se realiza en ausencia de consenso". (Star, 2010, p. 20) 